\title{
Collaborative virtual environment to facilitate game design evaluation with children with ASC
}

\author{
Tessa Roper ${ }^{1}$, Laura Millen Dutka, Sue Cobb ${ }^{2 *}$ and Harshada Patel ${ }^{3}$ \\ Human Factors Research Group, Faculty of Engineering, University of Nottingham, \\ Nottingham, UK \\ *corresponding author \\ \{ezztbr ${ }^{1} ;$ epzsvc ${ }^{2} ;$ epzhp $\left.{ }^{3}\right\} @$ exmail.nottingham.ac.uk
}

\begin{abstract}
Involvement of children with autism spectrum conditions (ASC) in the design of new educational technology is becoming more prevalent. Despite potential barriers due to communication and ideation difficulties for children with ASC, adapted participatory design methods can successfully facilitate their direct involvement. Nonetheless, methods requiring face-to-face communication can still be difficult for children with ASC and research suggests that technology mediation could facilitate their contribution. This study explores the use of collaborative virtual environments (CVEs) as a medium through which students evaluated existing computer games and offered suggestions for game development. CVEs in which the users were represented by (a) avatars and (b) video-pods were compared to a faceto-face condition. Twelve typically developing (aged 8-9 years), 12 higher ability ASC (12-14) and 4 lower ability ASC children (12-14) participated. All student groups preferred the video-pod CVE and students with ASC were generally better able to contribute effectively through this medium than face-to-face.
\end{abstract}

Keywords: Participatory design; Autism; Virtual Environments; Evaluation;

Educational technology

\section{Introduction}

It is recognised that the use of computer technology and virtual environments can be beneficial and appealing for children with autism spectrum conditions (ASC). Children 
with ASC seem to be drawn to technology (Goldsmith \& LeBlanc, 2004) and there are many anecdotal accounts that report children enjoying using computer technology over other types of interactions (Barry \& Pitt, 2006; Battocchi et al., 2008; Benton, Johnson, Brosnan, Ashwin, \& Grawemeyer, 2011; Goldsmith \& LeBlanc, 2004; Hardy, Ogden, Newman, \& Cooper, 2002; Keay-Bright, 2007). In design research it is considered good practice to involve end-users in the design process to ensure that their needs and requirements are appropriately represented. For educational technology, use of participatory design (PD) methods over the last 20 years has established a variety of techniques for involvement of children directly in the design process of new technology development (e.g. Bekker, Beusmans, Keyson, \& Lloyd, 2003; Druin, 1999; Druin \& Fast, 2002; Fails, Guha \& Druin, 2013; Garzotto, 2008; Hall, Woods, \& Aylett, 2006; Markopoulos \& Bekker, 2003). More recently, involvement of children with special educational needs and disability (SEND), including $\mathrm{ASC}$ in the design of new educational technology is becoming more prevalent (see Benton and Johnson, 2015 for a comprehensive review). However, children with ASC are involved less frequently in technology design than their typically developing peers, and often with a more limited role (Guha, Druin \& Fails, 2008). An adapted approach to the PD method is often required when seeking to involve children with autism due to their specific needs (see, for example, Benton et al., 2011; Hourcade, 2017; Leo \& Leroy, 2008; Millen, Cobb, \& Patel, 2011; Spiel, Malinverni, Good, \& Frauenberger, 2017).

Virtual reality/virtual environments (VR/VEs) have been a particular area of interest and potential for researchers when considering technological innovations for children with ASC (Parsons et al., 2000; Parsons and Cobb, 2011). The COSPATIAL project, for example, focused on the use of Collaborative Virtual Environment (CVE) technology for supporting and developing communication skills for children with autism (Parsons, Millen, Garib-Penna, \& Cobb, 2011). CVEs offer a way for students with ASC to communicate without the need for face-to-face communication which they may find difficult (Parsons et al., 2011); social cues which can cause barriers to people with autism feeling able to communicate are lowered in VEs (Stendal \& Balandin, 2015). There are further several potential benefits of VE technologies for 
users with autism, as described by Myles, Swanson, Holverstott, and Duncan (2007): "the virtual environment is one form of computer-based learning that has advantages for people with autism in that computer-based programs are logical, predictable, impersonal, and limit distractions and anxiety while permitting the user to repeat a lesson as many times as necessary to learn the material or skill taught" (Myles et al., 2007, pp. 397).

A number of recent projects have explored these benefits; for example, Cheng et al. (2015) found that a 3D VE was effective in improving social understanding and skills in children with ASC; Didehbani, Allen, Kandalaft, Krawczyk, and Chapman (2016) found that a VR system was effective in training social skills to children with highfunctioning autism, who showed improvements in measures of Theory of Mind, affect recognition, and analogical reasoning; and Schuller et al. (2015) discuss improvements in emotion recognition and socialisation following intervention using games in a Virtual World. Ringland, Wolf, Boyd, Baldwin, and Hayes (2016) describe the appropriation of the popular online multi-user virtual world Minecraft to create the 'Autcraft' online community, noting the value of enabling children with autism to build their own virtual world. In a recent review, Newbutt (2014) describes several examples of how virtual worlds, such as Second Life, are being used for cognitive and social communication training of communities of young adults with autism, elsewhere noting that "VR holds promise for social improvement in autism by offering a platform to safely practice and integrate social cues that may improve social skills, social cognition, and social functioning." (Newbutt, Sung, Kuo, \& Leahy, 2017, p.237)

This paper extends on the increasing body of research around the benefits afforded by CVEs for children with autism, by considering the CVE itself as a medium through which to facilitate the involvement of ASC children in the design process of new technologies. If children with ASC are potentially able to communicate more effectively and readily with another person through the computer-mediation offered by a CVE, then this technology may also be used to mediate participatory design sessions. This paper presents a qualitative study which investigates whether children with autism can effectively participate in a game evaluation activity through the 
medium of a CVE, using a custom-made CVE called the Game Review Room (GRR). This contributes to the broader objective of improving participation of children with autism in the design of technology applications.

\section{Aims}

The main objective of this study was to evaluate the potential use of a CVE for supporting design evaluation activities with children with ASC. There were three specific aims:

(1) Investigate whether the GRR CVE enabled children with ASC and Typically Developing (TD) children to communicate their ideas and maintain engagement in a PD activity.

(2) Compare the effectiveness of the CVE session with a non-computer-mediated session (face-to-face).

(3) Investigate the suitability of the CVE design and obtain feedback from students about acceptance of the technology and identify ways in which the CVE could be improved.

\section{Participants}

This study involved the following groups of participants:

(1) Twelve typically developing students (age range: 8-9 years; 3 female, 9 male).

(2) Twelve students with an ASC or Asperger's Syndrome (higher ability - age range: $12-14$ years; 1 female, 11 male).

(3) Four students with an ASC (lower ability - age range: 12-14 years; 4 male).

All of the TD students attended the same mainstream primary school. The students with ASC (higher ability) were recruited from three schools: two mainstream secondary schools and one ASC specialist school. The students with ASC (lower ability) were recruited from one ASC specialist school and one special needs specialist school. Participants with ASC were selected by a teacher at each school based on the students' year group and diagnosis criteria specified by the facilitator (Year 7, 8 and 9, aged between 12 and 14 years old with a diagnosis of ASC, high-functioning autism (HFA) or Asperger's Syndrome (AS) with verbal communication ability). Information about the participants with ASC, as provided by their teachers at the time of participation, is shown in Table 1 and

Table 2. TD participants were selected by a teacher at each school based on the students' year group specified by the facilitator (Year 3 and 4, aged between 8 and 9 
years old). Recruitment for all groups was informed by discussions with teachers to ensure selection of appropriate participants, including ensuring that the activity was suitable for their individual abilities; for this reason, the TD children selected were younger than the ASC groups.

Table 1: Participants - students with autism (higher ability)

\begin{tabular}{|c|c|c|c|c|}
\hline Student & Sex & Age & Diagnosis & Setting \\
\hline HA1 & Male & 12 & $\begin{array}{l}\text { Autism with moderate } \\
\text { learning difficulties (MLD) }\end{array}$ & Mainstream secondary school \\
\hline HA2 & Male & 12 & Autism with MLD & Mainstream secondary school \\
\hline HA3 & Male & 14 & $\begin{array}{l}\text { Mild autism and learning } \\
\text { difficulties }\end{array}$ & Mainstream secondary school \\
\hline HA4 & Male & 13 & $\begin{array}{l}\text { ASC, BESD (Behaviour, } \\
\text { Emotional \& Social Difficulty) } \\
\text { and ADHD. }\end{array}$ & Mainstream secondary school \\
\hline HA5 & Male & 13 & ASC, BESD and Dysgraphia & Mainstream secondary school \\
\hline HA6 & Male & 12 & Asperger's Syndrome (AS) & Mainstream secondary school \\
\hline HA7 & Female & 14 & ASC & Mainstream secondary school \\
\hline HA8 & Male & 12 & $\begin{array}{l}\text { AS and PDA (Pathological } \\
\text { demand avoidance syndrome) }\end{array}$ & Mainstream secondary school \\
\hline HA9 & Male & 14 & AS, MLD and ADHD & Mainstream secondary school \\
\hline HA10 & Male & 14 & ASC and PDA & Autism specialist school \\
\hline HA11 & Male & 12 & ASC and ADHD & Mainstream secondary school \\
\hline HA12 & Male & 13 & ASC and PDA & Autism specialist school \\
\hline
\end{tabular}

Table 2: Participants - students with autism (lower ability)

\begin{tabular}{|l|l|l|l|l|}
\hline Student & Sex & Age & ASC & Setting \\
\hline LA1 & Male & 12 & Autism with limited verbal ability & Autism specialist school \\
\hline LA2 & Male & 12 & Autism with limited verbal ability & Autism specialist school \\
\hline LA3 & Male & 13 & Autism with limited verbal ability & Autism specialist school \\
\hline LA4 & Male & 14 & Autism with limited verbal ability & Autism specialist school \\
\hline
\end{tabular}




\section{The Game Review Room (GRR) CVE}

The GRR CVE was built using GLU4D technology (an audio-video communication CVE developed at the Mixed Reality Lab, University of Nottingham) and allows users to communicate with each other in a virtual room. The first stage of the research was to design and develop the GRR so that it would be suitable as a medium for the participants to explore and provide feedback on computer games. This required the facility for the children to view, and interact with, online computer games from within the CVE and then to communicate their ideas for game improvement to the researcher.

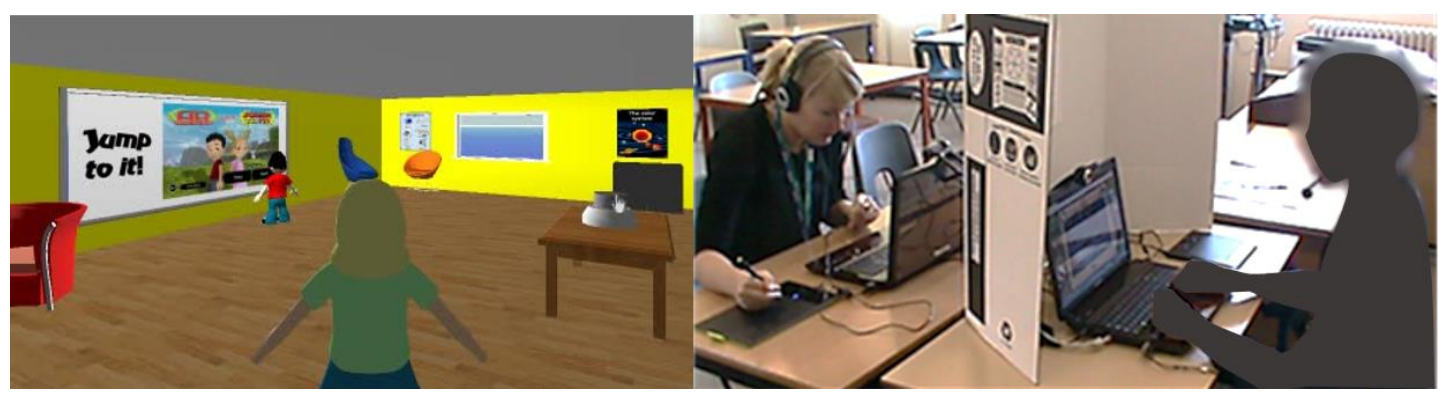

Figure 1: Screenshot of GRR CVE (left), a student and facilitator accessing the GRR CVE from separate laptops (right)

The GRR was designed specifically for use with children with ASC to be used as a meeting space in which a facilitator conducts interviews with children to find out their views on computer game design (Figure 1 - left). A child and facilitator can enter the virtual room from separate laptops and communicate with each other via a headset (Figure 1 - right). In the GRR a large virtual screen was used to display the computer game and the child could interact with it directly using the controls on their laptop.

The users were represented inside the GRR either by a computer-generated avatar (Figure 2 - left) or video-feed taken from a webcam and displayed inside a "video pod" (Figure 2 - right). 

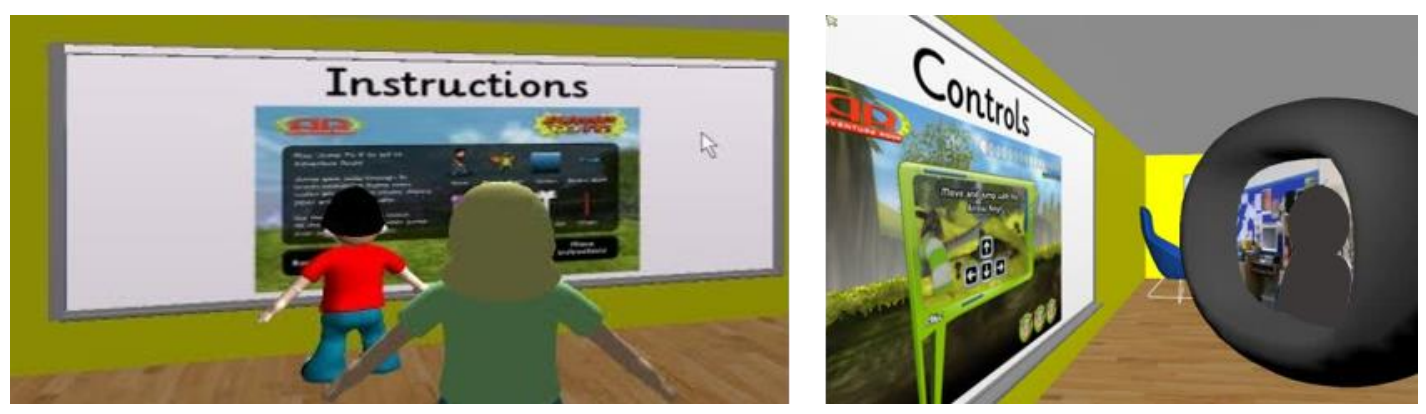

Figure 2: Players using the GRR CVE displayed as avatars (left) or via video pod (right)

\section{Development of the GRR}

To first determine the content and layout of the GRR CVE, a PD activity was carried out with a group of seven students with ASC (not involved in the main evaluation study reported below) between the ages of 15 and 17 years in their ICT lesson at an autism specialist school. The aim of the session was to generate ideas on the types of furniture the students might expect to see in the virtual room. The students were asked to produce one slide in PowerPoint that contained a list of objects that they would put in a virtual meeting space. The students then went on to produce a single slide on each object that they had listed by using Google Images and pasting the images into a PowerPoint presentation.

For logistical reasons we could not offer children a choice of the setting to be used, however children with ASC were involved in the design of the GRR layout and content which they were told would be a meeting place. The ideas generated by the students were used to populate the CVE. Repeated suggestions from the students were noted and included in the room design in order to create a CVE that had familiar properties as to what the students would expect to be there. Figures 1 and 2 show that the GRR was an open virtual meeting space including some items that may be found in a typical classroom, such as whiteboards and furniture familiar to children. However, the informal layout of the room appears more like the type of place children would play games rather than a setting where children would study. 
Based on our experience of working with children with ASC and their teachers within the COSPATIAL project, the design of the CVE was designed to suit the needs of children with ASC as follows:

- It was not over cluttered and too distracting yet would still be fun and informal;

- It included the furniture suggested by the children themselves to provide an environment that was meaningful and recognizable to them;

- It contained objects that were contextually accurate and therefore not distracting to the children;

- It was adaptable: objects and colours could be removed from the room to suit the needs of a specific child;

- It allowed the facilitator to provide visual cues within the virtual world to support the child's interactions.

These design considerations were intended to create an informal and relaxed environment where children would feel able to offer their thoughts and opinions to the facilitator. The final version of the GRR included a large button that was placed on a table in the centre of the room. This button was used to change the image on the interactive whiteboard in the CVE, which displayed visual prompts that were used to guide and structure the session.

\section{Study conditions}

The main research objective was to compare student communication using a computer-mediated communication medium (the GRR CVE) with an equivalent task in a non-computer-mediated (face-to-face) condition. However, we were also interested to learn whether the type of user representation within the CVE would have any impact.

To determine the optimal representation of users in the GRR, the design evaluation sessions in this study were conducted in three modes:

(1) GRR with computer generated avatars (Avatar condition) (Figure 3).

(2) GRR with video pods (Mixed Reality (MR) condition) (Figure 4).

(3) Face-to-face/non-computer-mediated session (F2F condition) (Figure 5). 
Video pod representation was included in the study as it provided a mode of communication that presents features of both of the other two representations; a live video feed of the child and the facilitator displayed via video pods allowed them to see each other directly (similar to the F2F condition) but only from inside the CVE. Thus, the participants did not need to be physically collocated, as in the F2F condition, and could use the potential benefits of a computer-mediated option including the physical distancing mechanism provided by the CVE.

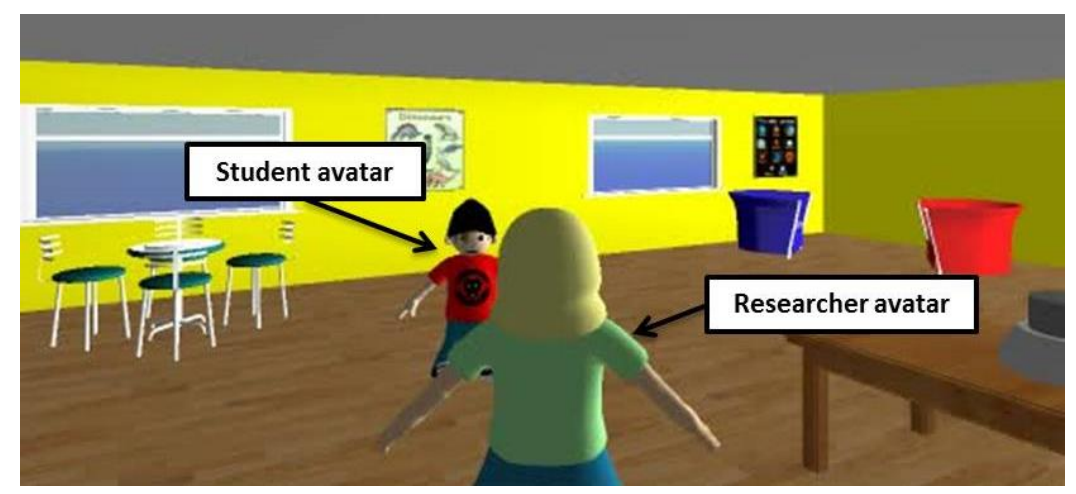

Figure 3: GRR CVE using avatars (Avatar condition)

The video pods were computer-generated cone-shaped graphics that displayed a centrally located video-feed of the user. The video was a form of video-mediated communication that allowed users to view other participants in real-time. The video streaming technology allowed the application to capture and distribute a live webcam feed that was then displayed on the recipient's pod. Webcams on each user's computer were used to capture the video steam in real time.

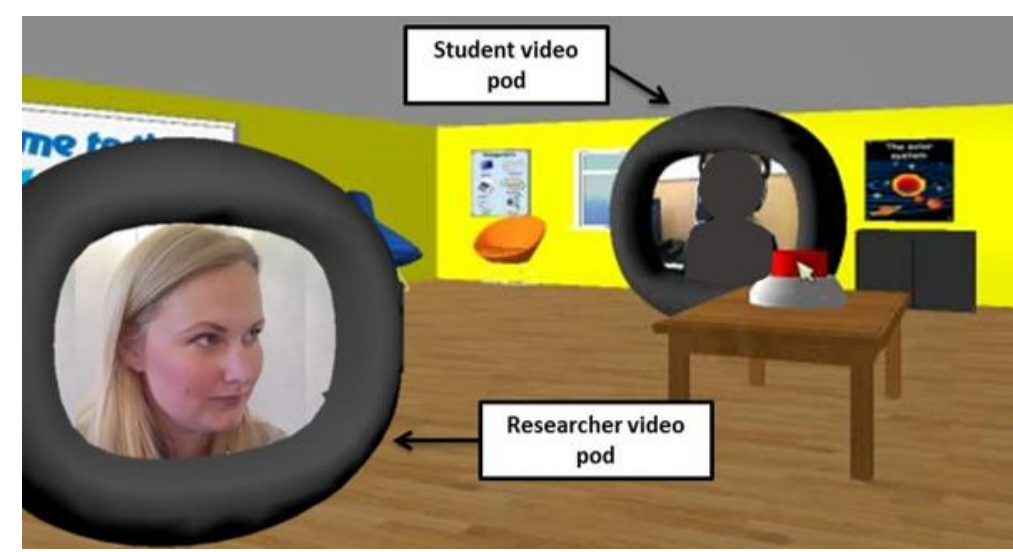

Figure 4: GRR using video pods (MR condition) 
The non-computer-mediated session involved a student and facilitator sitting next to each other (Figure 5). No computers were used. Instead, printed materials (the same as the images displayed on the whiteboard in the VE conditions) were used to structure the session.

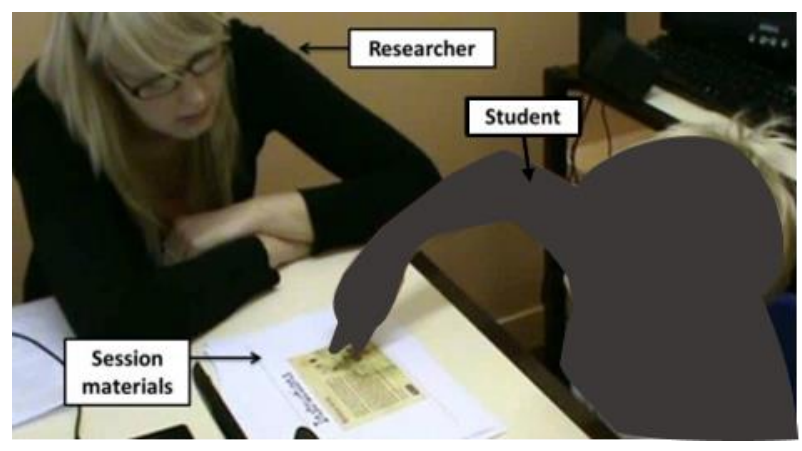

Figure 5: Non-computer-mediated session (F2F condition)

\section{Equipment}

The GRR was run on two laptops, connected with a local area network cable. Each laptop was connected to a Logitech USB webcam. Children were given noise cancelling headphones.

Sessions were recorded in two ways. First, a Sony video camera was used to film the participants' interactions in each study condition. Second, in the computer-mediated conditions, screen capture software called Fraps (www.fraps.com) was used to capture the activity within the CVE on both the child's and facilitator's laptops.

\section{Procedure}

Sessions were carefully planned to accommodate the needs of children with autism, following an approach discussed in Millen et al. (2011) and Cobb, Hawkins, Millen, and Wilson (2015). Prior to the day of the first session, the student was introduced to the facilitator by a school staff member. The school was also provided with a photograph of the facilitator so that a school staff member could remind the student of the upcoming sessions. Each student then participated in three 60-minute sessions, over three weeks. All the sessions involved the same facilitator, and all sessions were one-to-one. Each session followed the same structure and comprised four main components, described below. 


\subsection{Session introduction}

This component involved the facilitator explaining to the student the structure of the session and what was expected of them. The main aims of the session were discussed with the student. A printed timetable with visual prompts was used. This timetable was used throughout the session to provide the student with an understanding of the purpose of the session activities and to ease any anxiety they may have had regarding upcoming activities. Visual timetables are a well-established method for guiding students with autism through daily activities.

\subsection{Playing commercially available computer games}

The next task involved playing one of three commercially available computer games for approximately ten minutes. The game play was the main focus of the subsequent interview discussion, as this was the game that the student would be reviewing. The 'Way of the Warrior' was a single player, online browser game based on a CBBC television programme. 'Jump to It!' was a single player web-based browser game produced for CBBC. Easy and hard difficulty modes were offered to the player. 'Waterlogged' was a web-based browser game that was hosted by the National Geographic website.

The games were chosen due to their simple nature but also the common design characteristics that the games shared, e.g. characters, rewards, lives and obstacles. All three games could be played a number of times from start to finish within a tenminute period (depending on the ability of the user). This format was chosen as it allowed the student to try the game several times and therefore be in a position to critique the game and suggest improvements.

\subsection{Interview discussion with facilitator}

This task involved asking the student questions about the design features of the game just played and ideas for development of a new game. For each session a different game was reviewed and the interview was conducted in one of the three conditions (in counter balanced order for the TD and ASC (higher) children, however the games were played in the same order across the three weeks): 
- GRR CVE with avatars (Avatar)

- GRR CVE with video pods (MR)

- Non-computer-mediated interview (F2F)

The interview plan was prepared with the help of ASC specialist teachers. The interview was designed to focus on key game features such as rewards, lives, challenges and characters.

\subsection{Feedback questionnaire}

Students completed questionnaires at the end of each session to rate their enjoyment during that session as well as choosing which interview method they preferred. These questionnaires were reviewed by an autism-specialist teacher for appropriateness prior to use. The teacher gave feedback on the length, structure and layout of the questionnaire and the complexity of the language used. The first version of the questionnaire was simplified and shortened in response to this feedback and the second version was evaluated again for clarity and to check it was the right length. The students were also asked to rate each of the conditions according to how much they liked the session using a five-point Likert "smiley" scale (adapted from Read \& MacFarlane, 2006), as shown in Figure 6. 


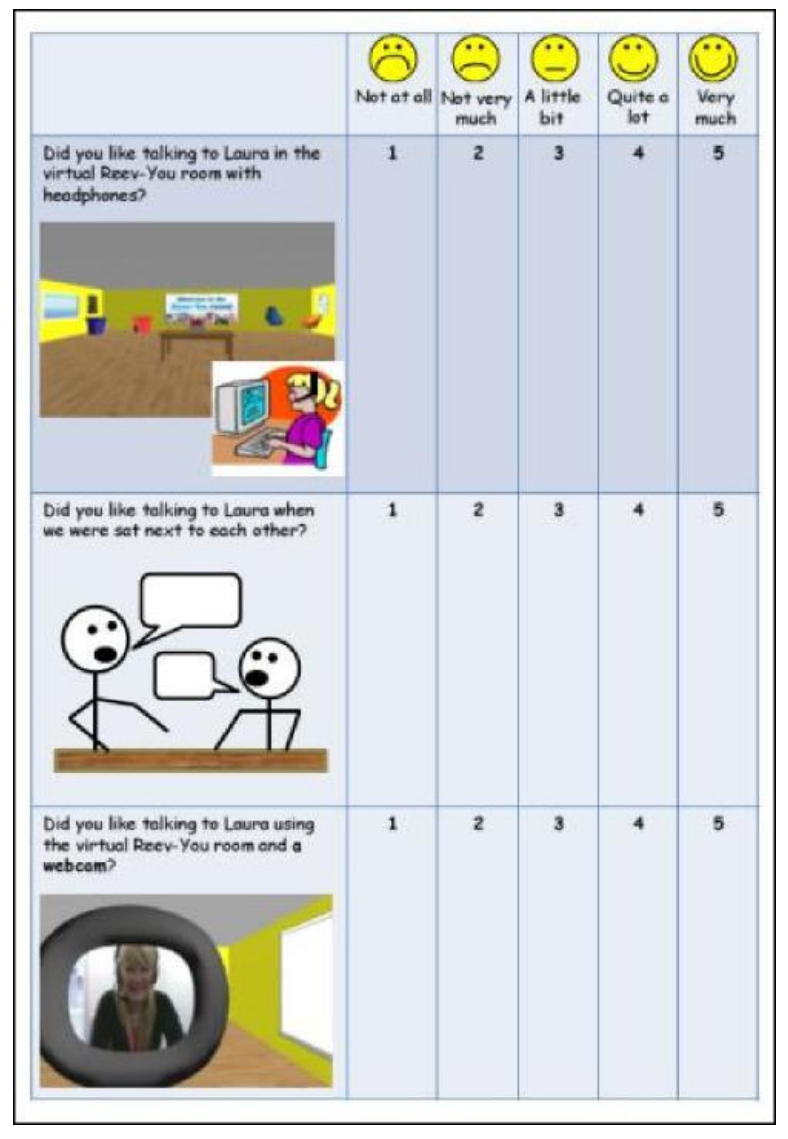

Figure 6: Likert "smiley" scales used in sessions

\section{Analysis approach}

A qualitative, theme-based analysis approach was taken to assess the potential of the GRR as a tool for supporting PD with children with ASC. This was based on the approach used by Benford and Standen (2009) in their study of adults with Asperger's Syndrome and High Functioning Autism and communication via the internet.

The assistance of two experienced teachers (not involved in the selection of children to participate in the study) was enlisted in order to identify themes that would provide the basis of analysis. A combination of deductive and inductive approaches were used to generate the analysis criteria. First, a workshop was held with the teachers to generate themes. During the workshop the teachers watched five sample videos that had been selected by the researcher to show a range of student responses and the aims of the research were discussed. The team, including the researcher, identified three broad categories through a deductive approach drawing on the aims 
of the research that were informed by the literature. These three categories were: engagement, ability to critique, and ability to generate ideas.

These categories were considered to be important in relation to understanding each student's performance, as all three are key to participation in a PD scenario. These categories are particularly important in the context of working with children with ASC. For example, children with ASC may have limited attention span and the facilitator may struggle to maintain engagement throughout the session (Mesibov \& Shea, 2010). Also, children with ASC often find it difficult to express their opinions and provide critical feedback which may mean that they have a limited ability to critique existing technology (Frauenberger, Good, Alcorn, \& Pain, 2013). Finally, children with ASC have limited imagination skills and therefore they may have an inability to generate ideas (Benton et al., 2011).

The categories for the analysis criteria were broad due to the wide range of abilities between the students. An inductive approach through collaboration with the teachers was used to generate key performance indicators for each of the three main categories (see Table 3). The teachers worked together to produce a list of behaviours or questions to consider from watching the sample of videos and these were discussed with the researcher. They then watched all of the videos independently from each other to validate the categories and, once complete, both teachers confirmed that they felt that the categories were relevant.

Table 3. Key performance indicators for each category relating to PD performance

\begin{tabular}{|l|l|}
\hline Category & Prompts / Subcategories \\
\hline engagement & $\begin{array}{l}\text { Is the student looking at the screen? } \\
\text { Is the student listening to questions and providing answers? } \\
\text { Are the answers relevant? } \\
\text { Is the student displaying signs of fatigue or boredom, e.g. yawning, leaning } \\
\text { across the table? }\end{array}$ \\
\hline Ability to & $\begin{array}{l}\text { Are they able to provide an opinion (positive or negative) on the game? } \\
\text { Are they able to identify areas of the game that they are not happy with? } \\
\text { Are they able to provide justification for their answers? } \\
\text { Does the student draw on personal experience? }\end{array}$ \\
\hline
\end{tabular}




\begin{tabular}{|l|l|}
\hline & $\begin{array}{l}\text { Are their answers relevant/sensible? } \\
\text { Does the student consider other users' needs (e.g. younger users)? }\end{array}$ \\
\hline $\begin{array}{l}\text { Ability to } \\
\text { generate } \\
\text { ideas }\end{array}$ & $\begin{array}{l}\text { Is the student able to generate new ideas? } \\
\text { Are the ideas well explained? } \\
\text { Are the ideas sensible? }\end{array}$ \\
\hline
\end{tabular}

The teachers involved in the generation of the themes reported that they felt it was important that the analysis was undertaken by either someone who knew the student or by a person who was present at the session. Therefore, using the three themes that were generated with the teachers, the videos were retrospectively analysed by the facilitator who was able to draw on experiences of the session in addition to the video data.

In addition, due to differences in ability between the children in the sessions, and between children on the autism spectrum generally, it was deemed important to collect feedback from teachers who knew the individual children that took part. For example, some of the students with ASC may only respond to interview questions with two or three words which may indicate to a person who does not know them that the conversation is poor; however, this may be two or three words more than usual. Five teachers participated in this analysis for 12 of the students with ASC. All five teachers had at least one year's experience of working with the individual student. The teachers were asked to provide their general feedback on the videos. Unfortunately due to the time and availability constraints of the teachers at one of the schools, familiar teacher feedback was not provided for four of the students.

The facilitator's retrospective video analysis was broken down into two stages: qualitative observations and structured ranking. The first stage involved watching each session video and considering the above prompts for each topic discussed in the interview (e.g. Rewards, Characters, and Controls). The facilitator then recorded comments under each theme (engagement, ability to critique, ability to generate ideas) for each topic. 
Stage 2 involved comparing each student's three sessions and ranking each session according to their engagement, ability to critique and ability to generate ideas. It was deemed necessary to apply a structured approach to the themes to make these judgements of success between each mode or condition in order to understand which conditions provided the optimal experience for PD with students with ASC and to understand the differences between the groups of students. The facilitator revisited the comments provided under each theme across all topics and ranked the conditions from most successful to least successful and recorded why this decision was made.

The results are presented below in three key areas:

- Observation of student performance (comparison between TD and ASC) by condition: Investigate whether the GRR CVE enabled children with ASC and TD children to communicate their ideas, critique an existing game and maintain engagement in a PD activity.

- Student responses to the CVEs (comparison between conditions and TD/ASC): Presentation of questionnaire results.

- Suitability of the CVE: Examination of the suitability of the CVE design from the student and facilitator perspective and identification of areas of improvement.

\section{Results}

The results from the retrospective video analysis are presented below by theme: engagement, ability to critique and ability to generate ideas. A comparison between representation types is provided. For children with ASC, some descriptive commentaries with examples from the sessions are presented, to highlight the behaviours demonstrated in different conditions. Note that a "traffic light" colour coding is used for all rankings, whereby green corresponds with the most successful session, amber the second most successful, and red the least successful. 


\section{Engagement}

\section{1 TD students}

The results of the quantitative ranking activity are shown in Table 4. The face-to-face (non-computer-mediated) condition was rated the best for 10 out of 12 TD students when all conditions were compared. The Avatar and MR conditions were similar to each other although for two students the Avatar condition was slightly better.

Table 4: TD students ranking results for 'engagement'

\begin{tabular}{|r|c|c|c|c|}
\hline & Green & Amber & Red & Total \\
\hline Avatar & 2 & 2 & 8 & 12 \\
\hline MR & 0 & 9 & 3 & 12 \\
\hline F2F & 10 & 1 & 1 & 12 \\
\hline
\end{tabular}

\subsection{Students with ASC (higher ability)}

Students with ASC (higher ability) had better engagement overall in the Avatar condition with 5 students out of the 12 performing the best for engagement level in this condition (see Table 5). The MR condition accounted for 4 students' best performances whereas the $\mathrm{F} 2 \mathrm{~F}$ condition accounted for three best performances. This indicated that the students with ASC were performing better in the computermediated conditions overall.

Table 5: Students with ASC (higher ability) ranking results for 'engagement'

\begin{tabular}{|r|c|c|c|c|}
\hline & Green & Amber & Red & Total \\
\hline Avatar & 5 & 5 & 2 & 12 \\
\hline MR & 4 & 2 & 6 & 12 \\
\hline F2F & 3 & 5 & 4 & 12 \\
\hline
\end{tabular}

The MR condition re-introduced an element of the "face-to-face" nature of the interaction. This may have contributed to 6 out of 12 of the least successful performances being in the MR condition. In comparison, the Avatar condition accounted for only two of the least successful performances, with the F2F condition accounting for the other four. 
An example of successful engagement in the computer-mediated conditions is presented by student HA3. This student struggled with answers in all three interview conditions and in each interview there were long pauses, particularly when questions required some abstract thought and were not direct. However, it was very clear in the F2F interview that the student was uncomfortable and not as relaxed as in the Avatar interview and particularly the MR interview. In the F2F condition, the student fiddled and fidgeted, avoided any eye contact and tired very easily. In contrast, in the MR condition interview, he became quite conversational and his answers were longer and more descriptive.

Common features in many of the ASC Higher Ability Student interviews were indications of discomfort such as fiddling with headphones, shuffling in the seat, fidgeting and indicators of slight detachment such as yawning and looking around. In addition, some students tired more quickly than in the other two conditions as though the F2F condition was putting extra strain on them and their attention. For example, very early in the F2F interview, student HA10 began running his hand through his hair, yawning and rubbing his face. In the computer-mediated conditions indications of tiredness did not appear until much later and were not as noticeable. HA10's teacher commented:

"He was more relaxed when not face-to-face. He did less lounging on the table and less fidgeting, showing he was more confident using the virtual communication rather than in person, even though his answers were not always as detailed."

TD students are more likely to use visual cues, body language and facial expressions when communicating with others (Mundy, Sigman, Ungerer, \& Sherman, 1987). Students with ASC often do not rely on, or cannot read, visual cues such as facial expressions (Mesibov \& Shea, 2010). Reading these visual cues is therefore not an essential aspect of communication with others and this may contribute to the difference in performance in computer-mediated versus non-computer-mediated conditions compared to the TD results. Research has shown that the types of visual cues that non-autistic persons find natural may be distracting to students with ASC and this may explain improved performance in the Avatar and MR conditions. The 
Avatar condition completely removed these visual cues and allowed the student to focus on the task at hand and therefore potentially contributed to the better performance in these conditions.

\subsection{Students with ASC (lower ability)}

Engagement was best in the MR condition for three of the four students in the study with autism and of lower ability (Table 6).

Table 6: Students with ASC (lower ability) ranking results for 'engagement'

\begin{tabular}{|r|c|c|c|c|}
\hline & Green & Amber & Red & Total \\
\hline Avatar & 0 & 2 & 2 & 4 \\
\hline MR & 3 & 1 & 0 & 4 \\
\hline F2F & 1 & 1 & 2 & 4 \\
\hline
\end{tabular}

Students LA3 and LA2 struggled throughout all three condition interviews. The responses of Student LA1 in all three condition interviews were typically short (a number of "Yeah" responses), interspersed with long pauses and occasionally a shake or nod of the head or no response at all. He tired quickly and was easily distracted. However, LA1's teacher commented positively on the student's ability in the Avatar session:

"Was getting tired near the end but communicated better than he usually does during that time span. Must have been motivated to stay at the activity/computer as he would usually walk away if questions were difficult or challenging him to think about something. A typical response from LA1 when asked to consider how to make things better or what to add to the room he will say 'don't know'".

The negative characteristics displayed in the computer-mediated conditions however were more accentuated in the F2F condition where there was no eye contact and where it was obvious that the student was in discomfort being in the immediate company of the interviewer and being the subject of her attention. At first, he would answer only with one word and move his arms and hands around his head, almost to hide his face behind them but he very quickly became even more detached and clearly responded only with the aim of getting it over with. 


\section{Ability to critique}

\subsection{TD Students}

A similar result to that of 'engagement' was observed in terms of the students' ability to critique (Table 7). The F2F condition was considerably better than the other two and was the best overall condition for 6 of the 12 students. The Avatar and MR conditions were again close to each other with both identified as the most successful for 3 students each. However, ten of the sessions that were rated as least successful took place in the Avatar (6) and MR (4) conditions.

Table 7: TD students ranking results for 'ability to critique'

\begin{tabular}{|r|c|c|c|c|}
\hline & Green & Amber & Red & Total \\
\hline Avatar & 3 & 3 & 6 & 12 \\
\hline MR & 3 & 5 & 4 & 12 \\
\hline F2F & 6 & 4 & 2 & 12 \\
\hline
\end{tabular}

The ability to critique could also be linked to a student's 'willingness to critique' and as such may reflect the level of engagement in each condition. The greater focus generated by the immediate presence of the facilitator in the F2F condition may well have resulted in better answers in this category. In eight of the sessions where the students' ability to critique was considered the best in comparison to the other two conditions, their engagement levels were also considered to be the best.

\subsection{Students with ASC (higher ability)}

Students with autism (higher ability) showed a better ability to critique overall in the computer-mediated conditions, with the Avatar condition accounting for six of the best performances, the MR condition accounting for three and the F2F accounting for the other three (Table ).

Table 8: Students with ASC (higher ability) ranking results for 'ability to critique'

\begin{tabular}{|r|c|c|c|c|}
\hline & Green & Amber & Red & Total \\
\hline Avatar & 6 & 1 & 5 & 12 \\
\hline MR & 3 & 8 & 1 & 12 \\
\hline F2F & 3 & 3 & 6 & 12 \\
\hline
\end{tabular}


Interestingly and in contrast to the results for 'engagement', the MR condition accounted for only one of the poorest performances, with Avatar having five poor performances and F2F having six. In the MR condition, the delivery may have been novel enough and distant enough (i.e. the student was not actually sat in front of the facilitator) to engage the student and allow them to pick and choose which cues to process in a safer, less pressured context. In addition, it is likely that the facilitator's performance was better in this condition over the Avatar condition due to the facilitator's ability to observe the student via the webcam and therefore better monitor their behaviour and engagement and subsequently adapt questions and timings accordingly.

Student HA6 was a good example of how similar the performance could be on each of the interviews. He showed a good ability to critique in all three interviews making sensible points and offering suggestions for improvements to the game. However, his performance in the Avatar condition was rated as the most successful because his answers were more detailed. For example, in the Avatar interview, he commented on the instruction page of the game, "This is an entire bunch of writing. Really big words that younger people wouldn't understand ... I don't even know what that means" (pointing to the screen). In the MR condition interview his answers were carefully considered and in some detail. He described the game saying, "It is about jumping over obstacles and stuff like that ... to get to the levels and progress ... get to that fat thing ...Is it a robot? It's quite good," and, "You have to collect cogs... I don't really know why ". However, in the F2F interviews, his answers tended to be less well thought through and shorter in general, saying of the characters, "They're annoying ... I just like colourful characters to choose them ...his head's too big for his body," and, "I don't know why it (one of the characters) is a monkey. Get rid of him, he's pointless." This suggests that the student was more able to provide detailed answers in the computer-mediated sessions, perhaps due to him being more relaxed and in a non-face-to-face situation. 


\subsection{Students with ASC (lower ability)}

The MR condition accounted for three out of four of the best performances in this category and all of the students' least successful performances were in the F2F condition (Table 9).

Table 9: Students with ASC (lower ability) ranking results for 'ability to critique'

\begin{tabular}{|r|c|c|c|c|}
\hline & Green & Amber & Red & Total \\
\hline Avatar & 1 & 3 & 0 & 4 \\
\hline MR & 3 & 1 & 0 & 4 \\
\hline F2F & 0 & 0 & 4 & 4 \\
\hline
\end{tabular}

As mentioned previously, students with ASC are likely to find the thought processes necessary for the 'ability to critique' and the 'ability to generate ideas' more challenging. This was certainly the case with Students LA1 and LA2. Student LA1 often responded by repeating the words of the interviewer and whispering to himself. Student LA2 made a greater contribution, particularly in the MR condition interview and responded better to direct questions. Answers were still brief and in the form of phrases that were sometimes unconnected with the question but he continued to respond throughout. In the F2F interview his discomfort and early tiring prompted one-word answers that were clearly used as a way to avoid any unnecessary conversation or further description.

\section{Ability to generate ideas}

\subsection{TD Students}

In terms of their ability to generate ideas, TD students again performed the best in the F2F condition, with 8 out of 12 performing best (Table ). Following the same pattern as in the sections 'engagement' and 'ability to critique' the computermediated conditions produced only three best performances for MR and one for Avatar. MR and Avatar accounted for 10 of the 12 worst performances between them. 
Table 10: TD students ranking results for 'ability to generate ideas'

\begin{tabular}{|r|c|c|c|c|}
\hline & Green & Amber & Red & Total \\
\hline Avatar & 1 & 6 & 5 & 12 \\
\hline MR & 3 & 4 & 5 & 12 \\
\hline F2F & 8 & 2 & 2 & 12 \\
\hline
\end{tabular}

\subsection{Students with ASC (higher ability)}

Students with autism find abstract thought processes and concepts most difficult to deal with. It is therefore not surprising that the results in this section were almost too close to separate, with each of the three conditions accounting for four of the best performances (Table 11). However, most students ( 8 out of the 12) performed better in the computer-mediated conditions. For the poorest performances, the Avatar condition accounted for four, MR accounted for five and F2F accounted for three.

Table 11: Students with ASC (higher ability) ranking results for 'ability to generate ideas'

\begin{tabular}{|r|c|c|c|c|}
\hline & Green & Amber & Red & Total \\
\hline Avatar & 4 & 4 & 4 & 12 \\
\hline MR & 4 & 3 & 5 & 12 \\
\hline F2F & 4 & 5 & 3 & 12 \\
\hline
\end{tabular}

Six of the 12 students in their Avatar interviews, six in the MR interviews and five in the F2F interviews received the same performance category in both 'ability to critique' and 'ability to generate ideas' categories, thus reinforcing the suggestion that these areas provided similar challenges to students with autism.

Perhaps most relevant to this investigation was that, overall, 8 of the 12 students who performed the best in the area of 'ability to generate Ideas' also performed the best in both of the other two categories in that condition; that is those 8 students found that the particular condition (Avatar, MR or F2F) suited them best and they, as a consequence, performed best in all three categories ('engagement', 'ability to critique' and 'ability to generate ideas').

Student HA5 was a good example of this pattern. He expressed good ideas in all three conditions. In the Avatar condition interview, he enthusiastically described a next level in imaginative detail suggesting, "A voice would give you tips how to do it 
(complete the task)" and that, "Navarn ... like it was the ultimate boss ever... you [would] have to defeat him ... the last level would be a race ". He went on to describe this final event as well as an additional three levels of difficulty.

In the MR session he expressed ideas of similar quality and with similar enthusiasm saying, "Why don't you give it about 25 levels? It could be like the elements of the earth... [like] thunder .... When you're flying a plane or fighting the boss where it gets it energy, when you see a line of energy, you go for it."

In the F2F session, there were fewer ideas as the interview went on but earlier he suggested things such as collecting rewards, "Like a bubble ... and if you got a certain number, you could be like an agent. He'll look like James Bond. You would need more time - give him 2 minutes and 20 seconds." He went on to expand these ideas but his ideas became fewer and less detailed as he appeared to become more tired.

\subsection{Students with ASC (lower ability)}

Many of the same limitations and challenges evident in the previous section were present in the students' ability to generate ideas. Four of the best performances were in the MR condition interview and Avatar and F2F accounted for two of the poorest performances each (Table 3).

Table 3: Students with ASC (lower ability) ranking results for 'ability to generate ideas'

\begin{tabular}{|r|c|c|c|c|}
\hline & Green & Amber & Red & Total \\
\hline Avatar & 0 & 2 & 2 & 4 \\
\hline MR & 4 & 0 & 0 & 4 \\
\hline F2F & 0 & 2 & 2 & 4 \\
\hline
\end{tabular}

For Students LA1 and LA2, responses were very limited and were often repetitions of the interviewer's question, occasionally with a one word, "yes" added. LA2's teacher said "He finds it difficult to make decisions or suggest his own ideas unless it is something that he has had previous experience of."

LA3 was able to offer suggestions for improving the current game and for new levels. He was most successful in this in the two computer-mediated conditions where for example he said (of a new game), "They can collect gold rings and ...err... they can 
collect err shields and stuff..." and "the feathers are white and err ...that means you've lost a life...you can have 10 lives or 20 lives... I think there should be a 1000 ... lives are going to be planets..." (This idea coming from a planet poster on wall in the virtual room) "I think that sounds very fun to me". In the F2F session, he again expressed some ideas but these were shorter and less detailed.

\section{Session Order}

When the results were examined in relation to session order, an interesting pattern was observed. We expected to see the most successful results in the final session as the students may perform better as they become familiarised with the task and the facilitator. We would expect this to be an even more prominent occurrence with students with ASC, as it is reasonable to expect that they may need longer than TD children to feel comfortable with a stranger and tend to communicate better with adults they feel comfortable with.

However, we actually saw a higher number of best performances in the first session across all groups. An explanation could be that, as the study took place in the respective schools of the participants, and the students had been previously introduced to the facilitator by their teachers, they were sufficiently comfortable in working with the facilitator from the first session and this did not change over time. Furthermore, the novelty of the task in the first session may have provided a motivation to the students that had worn off by the third session.

\section{Summary}

In summary, overall TD students performed better in the face-to-face condition potentially due to the opportunity it provides to rely on "natural" communication sources (body language, facial expressions). The Avatar condition fared the worst potentially due to the complete lack of opportunity to rely on visual cues during the interaction.

Students with ASC in the higher ability group performed better in the computermediated conditions perhaps due to the elimination or reduction in the potentially confusing and distracting social cues and expressions that students with ASC find 
difficult to read. For these students performance in the Avatar condition was overall higher than in the MR across the measures.

Students with ASC in the lower ability group performed much better in the computermediated conditions and in the MR condition in particular. This could be due again to the reduction of distracting social cues and the pressure of true face-to-face interaction. In this condition, the facilitator's ability to observe the student (facial expressions, body language) and respond to their needs, contributed to the MR condition being the most successful for this group. Nonetheless, the level of feedback and ideas provided was minimal and the task of providing criticism and generating new ideas was too difficult for this group of students.

\section{Student questionnaire results}

After completing all three sessions the students were individually asked which session they preferred and in which way they preferred talking to the facilitator. The students were asked to place a tick next to one of the three conditions to indicate their preference. The results of this question are shown in Table 13. Students with ASC (lower ability) struggled with the questionnaire, and their responses are therefore not reported here.

Table 13: Overall preference of conditions

\begin{tabular}{|l|l|l|l|l|}
\hline \multirow{2}{*}{ Participant group } & \multicolumn{2}{|l|}{ Overall preference at week 3 } & \multirow{2}{*}{ Total } \\
\cline { 2 - 5 } & Avatar & MR & F2F & \\
\hline ASC (higher ability) & 5 students & 7 students & 0 students & 12 \\
\hline TD & 4 students & 7 students & 1 student & 12 \\
\hline
\end{tabular}

In summary, students in both groups (TD and ASC) preferred the computer-mediated conditions (Avatar and MR). Only one TD student stated a preference for the noncomputer-mediated condition. The MR condition was marginally preferred over the Avatar condition - one student who stated the Avatar condition was their favourite said that this was because the avatar was easier to move around whereas the video pod in the MR condition was "too big" and therefore difficult to move around. 
The students were also asked to rate each of the conditions according to how much they liked the session using a five-point Likert scale with the anchors: not at all; not very much; a little bit; quite a lot; very much. Table 14 shows the averaged ratings across the data set for all the students by condition.

Table 14: Student average rating scores for each condition

\begin{tabular}{|l|l|l|l|}
\hline \multirow{2}{*}{} & \multicolumn{2}{|l|}{ Average rating scores } \\
\cline { 2 - 4 } & Avatar & MR & F2F \\
\hline ASC & 4.42 & 4.42 & 3.6 \\
\hline TD & 4.1 & 4.7 & 3.5 \\
\hline
\end{tabular}

Once again, the results show that for the ASC students there was a preference for the computer-mediated sessions over the non-computer-mediated sessions however there was no difference between ratings for the Avatar and MR conditions.

TD students rated the MR as the most favourable condition, with the Avatar condition second and F2F the least favourable.

In summary, overall, all students (TD and ASC) liked the computer-mediated sessions the most and F2F the least.

\section{Discussion}

While important research continues on the adaptation of traditional face-to-face UCD methods to support the involvement of children with autism (Benton et al., 2011; Hourcade, 2017; Leo \& Leroy, 2008; Millen et al., 2011; Spiel et al, 2017), this paper discusses an alternative or supplementary approach in which design sessions can be computer-mediated. We explored the use of CVEs for this purpose, drawing on their afforded benefits to support children with autism (Cheng et al., 2015; Didehbani et al., 2016; Myles et al., 2007; Parsons \& Cobb, 2011; Parsons et al., 2011; Parsons, Newbutt and Wallace, 2014; Schuller et al., 2015; Stendal \& Balandin, 2015). A CVE was adapted to facilitate sessions in which children review computer games, and a qualitative study explored whether this is a potentially valuable approach. A summary of the results for each of main aims of this study are provided below. 
Aim 1: Investigate whether the GRR CVE enabled children with ASC and TD children to communicate their ideas and maintain engagement in a PD activity.

The use of computer-mediated PD sessions for engaging with students with ASC showed some potential. The results suggested that conducting the interview in a CVE was more successful than face-to-face for students with ASC. Interestingly, while the computer-mediated conditions were preferred by both TD and HA groups, this did not correspond to an increase in performance in all cases. Notably, the TD children performed better in the F2F condition across all three performance categories, despite a clear subjective preference for the computer-mediated conditions. Thus, an increased subjective preference does not necessarily lead to improved performance, even for the measure of engagement, which might intuitively be expected to increase as a natural result of preference. This has important implications for future work, suggesting that a balance between preference and performance may need to be considered, with appropriate weight given to user research collecting data on both of these concepts.

Aim 2: Compare the effectiveness of the CVE session with a non-computer-mediated session (face-to-face).

TD students performed better in the face-to-face condition potentially due to the opportunity it provided them to rely on "natural" communication cues (body language, facial expressions). The Avatar condition fared the worst for TD students, possibly due to the complete lack of opportunity to rely on visual cues during the interaction. On the other hand, students with ASC (higher ability) performed better in the computer-mediated conditions, perhaps due to the elimination or reduction in the potentially confusing and distracting social cues and facial expressions that students with ASC find difficult to read. This is supported by the fact that the Avatar condition generally led to improved performances over the MR condition, which reintroduced some of these real world social cues.

Session order impact revealed that all participant groups tended to perform best in earlier sessions than later sessions. This suggests that unfamiliarity did not detract from performance in the current study, which may be partially due to planning 
sessions carefully to meet the needs of the user group, as discussed in Millen et al. (2011) and Cobb et al. (2015). This included advanced introductions by a familiar adult, visual prompts and timetables, clearly structured sessions, and adapted data collection materials (such as the "smiley" likert scale). These results therefore support the idea that relatively straightforward adaptations to PD sessions can be successful in removing typically perceived challenges in the involvement of children with autism. The decline in subsequent performance suggested that the novelty of the activity, combined with technology-mediated communication, motivated the students to engage in the task. However, the repetitive nature of the task may have led to declining interest over several sessions. In this study, task variation was provided by the use of different computer games as the subject of the PD activity. Whilst these were different games, they had been chosen because they had common design characteristics such as characters, rewards, lives and obstacles. Our intention was to provide similar activities so that we could compare student responses between the different study conditions. However, this may have caused an unintended 'novelty effect' in which the students were less interested in the activity over time. To retain student interest, it may have been more successful to apply a progressive approach in which different techniques for design review were applied in each session and built upon ideas generated in the previous session. A variety of techniques are described in participatory and co-design projects conducted over several sessions (e.g. Frauenberger, Makhaeva, \& Spiel, 2017; Gaudion, Hall, Myerson, \& Pellicano, 2015). For our task, techniques such as 'layered elaboration' (Walsh et al., 2010) and storyboard drawing methods (Walsh et al., 2012) would have offered more engaging activities for our participants. Indeed, this was observed in another study in which we extended the participatory design activity to include a drawing task (Millen, Cobb, Patel, \& Glover, 2012). However, in this study we specifically applied a similar task activity in each of the three sessions so that we could compare student responses between our study conditions.

Our results showed that students with ASC in the lower ability bracket performed much better in the computer-mediated conditions and in the MR condition in particular. This could be due again to the reduction of distracting social cues. In these 
cases, the facilitator's ability to see the student was paramount due to their limited verbal ability which contributed to the MR condition being the most successful. The differences between Avatar and MR are more pronounced than for the higher ability students. Despite enjoying using the technology, these students found the task of critiquing and generating new ideas extremely difficult.

Aim 3: Understand the suitability of the CVE design and obtain feedback from students about acceptance of the technology and identify ways in which the CVE could be improved.

The questionnaire results showed that students with ASC preferred using the CVE over the non-computer-mediated session. Moreover, evidence of better PD performance was demonstrated by both of the ASC groups in the computer-mediated sessions compared to the F2F condition. Our interpretation of this is that, utilising the preference of ASC children for computer-mediated communication, made it easier for them to provide better feedback and input into the design process. In addition, any anxiety about working with a less familiar adult was likely to be reduced if there was a strong interest in the technology. This again suggests that CVE technology for supporting PD sessions with children with ASC should be investigated further.

\section{Conclusions}

In summary, TD students performed better in the face-to-face condition, whilst students with ASC (higher ability) performed better in the computer-mediated conditions. The students with ASC (lower ability) showed better levels of engagement in the computer-mediated sessions, however the task of critiquing and generating new ideas remained difficult for these students overall. While most children across all groups generally preferred the computer-mediated conditions, this did not correspond with an increase in performance measures in all cases, particularly for the TD children. Future studies could elaborate on the relationship between preference and performance to guide researchers in the use of technology to support PD activities. 
It can be concluded that the use of a virtual tool for supporting PD with children with autism (higher ability) shows potential and therefore it will be of importance to explore this further. Differences between Avatar and MR conditions for the higher ability students should be investigated further. Suggestions for improving the CVE to enhance engagement, structure and facilitator monitoring should be considered in future work.

Given the demonstrated potential of the CVE to facilitate sessions with children with autism, it may be of further interest to investigate whether children are better able to participate in design activities generally following use of the CVE. It may be possible that a scaffold approach may prove effective, whereby initial involvement is mediated by computers and children then participate in face-to-face design sessions if children can become sufficiently comfortable, engaged, and familiar with researchers and research activities.

\section{Acknowledgements}

This study was supported by technology developed in the COSPATIAL project funded by the Seventh Framework Programme of the European Commission (Grant Agreement No. 231266). We thank the children who participated and the teachers and schools who supported this work. We also gratefully acknowledge Dr Tony Glover at the Mixed Reality Lab, University of Nottingham, who developed and modified the CVE for use in this study.

\section{References}

Barry, M. \& Pitt, I. (2006). Interaction design: a multidimensional approach for learners with autism. Proceedings of the 2006 conference on Interaction design and children. Tampere, Finland: ACM.

Battocchi, A., Gal, E., Sasson, B., Pianesdi, F., Venuti, P., Zancanaro, M. \& Weiss, P. L. (2008). Collaborative puzzle game - an interface for studying collaboration and social interaction for children who are typically developed or who have Autistic Spectrum Disorder. Proceedings of the 7th International conference series on disability, virtual reality and associated technologies (ICDVRAT), 2008, Maia, Portugal. 127-134.

Bekker, M., Beusmans, J., Keyson, D. \& Lloyd, P. (2003). KidReporter: a user requirements gathering technique for designing with children. Interacting with Computers, 15, 187202. doi:10.1016/S0953-5438(03) 955 00007-9

Benford, P. \& Standen, P. (2009). The internet: a comfortable communication medium for people with Asperger syndrome (AS) and high functioning autism (HFA)? Journal of Assistive Technologies, 3, 44-53. doi:10.1108/17549450200900015 
Benton, L., \& Johnson, H. (2015). Widening participation in technology design: A review of the involvement of children with special educational needs and disabilities. International Journal of Child-Computer Interaction, 3, 23-40. doi:10.1016/j.ijcci.2015.07.001

Benton, L., Johnson, H., Brosnan, M., Ashwin, E., \& Grawemeyer, B. (2011). IDEAS: An interface design experience for the autistic spectrum. Proceedings of the 2011 annual conference extended abstracts on Human factors in computing systems. Vancouver, BC, Canada: ACM.

Cheng, Y., Huang, C. L., \& Yang, C. S. (2015). Using a 3D immersive virtual environment system to enhance social understanding and social skills for children with autism spectrum disorders. Focus on Autism and Other Developmental Disabilities, 30(4), 222-236. doi:10.1177/1088357615583473

Cobb, S., Hawkins, T., Millen, L., \& Wilson, J. R. (2015). Design and development of 3D interactive environments for special educational needs. In: Kelly S. Hale and Kay M. Stanney (Eds.), Handbook of Virtual Environments: Design, Implementation, and Applications (2nd edn.), pp. 1075-1107. Stanford, California: CRC Press.

Didehbani, N., Allen, T., Kandalaft, M., Krawczyk, D., \& Chapman, S. (2016). Virtual reality social cognition training for children with high functioning autism. Computers in Human Behavior, 62, 703-711. doi:10.1016/j.chb.2016.04.033

Druin, A. (1999). Cooperative inquiry: Developing new technologies for children with children. Proceedings of the SIGCHI conference on Human factors in computing systems: the $\mathrm{CHI}$ is the limit. Pittsburgh, Pennsylvania, United States: ACM.

Druin, A., \& Fast, C. (2002). The child as learner, critic, inventor, and technology design partner: An analysis of three years of Swedish student journals. International Journal of Technology and Design Education, 12, 189-213. doi:10.1023/A:1020255806645

Fails, J. A., Guha, M. L., \& Druin, A. (2013). Methods and techniques for involving children in the design of new technology for children. Foundations and Trends in HumanComputer Interaction, 6(2), 85-166. doi:10.1561/1100000018

Frauenberger, C., Good, J., Alcorn, A., \& Pain, H. (2013). Conversing through and about technologies: Design critique as an opportunity to engage children with autism and broaden research(er) perspectives. International Journal of Child-Computer Interaction. doi:10.1016/j. ijcci.2013.02.001

Frauenberger, C., Makhaeva, J., \& Spiel, K. (2017, June). Blending methods: Developing participatory design sessions for autistic children. In Proceedings of the 2017 Conference on Interaction Design and Children (pp. 39-49). Stanford, CA.: ACM.

Garzotto, F. (2008). Broadening children's involvement as design partners: From technology to "Experience". Proceedings of the 7th international conference on Interaction design and children. Chicago, Illinois: ACM

Gaudion, K., Hall, A., Myerson, J., \& Pellicano, L. (2015). A designer's approach: How can autistic adults with learning disabilities be involved in the design process? CoDesign, 11(1), 49-69. doi:10.1080/15710882.2014.997829

Goldsmith, T. R., \& Leblanc, L. A. (2004). Use of technology in interventions for children with autism. Journal of Early and Intensive Behavioral Intervention, 1, 166-178. doi:10.1037/h0100287

Guha, M. L., Druin, A., \& Fails, J. A. 2008. Designing with and for children with special needs: An inclusionary model. Proceedings of the 7th international conference on Interaction design and children. Chicago, Illinois: ACM.

Hall, L., Woods, S., \& Aylett, R. (2006). FearNot! involving children in the design of a virtual learning environment. International Journal On Artificial Intelligence, 16, 327-351.

Hardy, C., Ogden, J., Newman, J., \& Cooper, S. (2002). Autism and ICT: 1020 A guide for teachers \& parents. London: Routledge. 
Hourcade, J. P. 2017. Participatory design with children on the autism spectrum. In Besty DiSalvo, Jason Yip, Elizabeth Bonsignore and Carl DiSalvo (Eds.) Participatory Design for Learning: Perspectives from Practice and Research pp 111 - 124. London: Routledge.

Keay-Bright, W. (2007). The reactive colours project: demonstrating participatory and collaborative design methods for the creation of software for autistic children. Design Principles and Practices, 1, 7-16. doi:10.18848/18331874/CGP/v01i02/37623

Leo, G. D. \& Leroy, G. (2008). Smartphones to facilitate communication and improve social skills of children with severe autism spectrum disorder: special education teachers as proxies. Proceedings of the 7th international conference on Interaction design and children. Chicago, Illinois: ACM.

Markopoulos, P., \& Bekker, M. (2003). Interaction design and children. Interacting with Computers, 15, 141-149. doi:10.1016/S0953-5438(03)00004-3

Mesibov, G., \& Shea, V. (2010). The TEACCH program in the era of evidence-based practice. Journal of Autism and Developmental Disorders, 40, 570-579. doi:10.1007/s10803009-0901-6

Millen, L., Cobb, S., \& Patel, H. (2011). Participatory design approach with children with autism. International Journal on Disability and Human Development, 10(4), 289-294. doi:10.1515/IJDHD.2011.048

Millen, L., Cobb, S. V. G., Patel, H., \& Glover, T. (2012). Collaborative virtual environment for conducting design sessions with students with autism spectrum conditions. In Proc. 9th Intl Conf. on Disability, Virtual Reality and Assoc. Technologies (pp. 269-278), Laval, France.

Mundy, P., Sigman, M., Ungerer, J., \& Sherman, T. (1987). Nonverbal communication and play correlates of language development in autistic children. Journal of Autism and Developmental Disorders., 17(3), 349-364. doi:10.1007/BF01487065

Myles, B. S., Swanson, T. C., Holverstott, J., \& Duncan, M. M. (2007). Autism Spectrum Disorders: A Handbook for Parents and Professionals, Westport, CT: Greenwood Publishing Group.

Newbutt, N. (2014). Representations of the self in classroom virtual worlds: An autism perspective. In: Felicia, P., ed. (2014) Game-based learning: challenges and opportunities. Newcastle upon Tyne, UK: Cambridge Scholars Publishing, pp. 165192.

Newbutt, N., Sung, C., Kuo, H. J., \& Leahy, M. J. (2017). The acceptance, challenges, and future applications of wearable technology and virtual reality to support people with autism spectrum disorders. In Recent Advances in Technologies for Inclusive WellBeing (pp. 221-241). Cham. Springer

Parsons, S., Beardon, L., Neale, H. R., Reynard, G., Eastgate, R., Wilson, J. R., ... Hopkins, E. (2000). Development of social skills amongst adults with Asperger's syndrome using virtual environments: The AS interactive project. In: ICDVRAT/UNIVERSITY OF READING, U., ed. Proceedings of the 3rd International Conference on Disability, Virtual Reality and Associated Technologies INTERNATIONAL JOURNAL OF HUMANCOMPUTER INTERACTION 13 (ICDVRAT), 23-25th September, Alghero, Italy. ICDVRAT/ University of Reading, UK, 163-172.

Parsons, S., \& Cobb, S. (2011). State-of-the art of virtual reality technologies for children on the autism spectrum. European Journal of Special Needs Education (EJSNE), 26(3), 355-366. doi:10.1080/ 08856257.2011.593831

Parsons, S., Millen, L., Garib-Penna, S., \& Cobb, S. (2011). Participatory design in the development of innovative technologies for children and young people on the autism spectrum: The COSPATIAL project. Journal of Assistive Technologies, 5, 29-34. doi:10.5042/jat.2011.0099 
Parsons, S., Newbutt, N., \& Wallace, S. (2014). Using virtual reality technology to support the learning of children on the autism spectrum. In K. Boser, M. Goodwin, \& S. Wayland (Eds.), Technology Tools for Students with Autism (pp. 63-84). Baltimore, MD: Brookes Publishing

Read, J. C., \& Macfarlane, S. (2006). Using the fun toolkit and other survey methods to gather opinions in child computer interaction. Proceedings of the 2006 conference on Interaction design and children. Tampere, Finland: ACM.

Ringland, K. E., Wolf, C. T., Boyd, L. E., Baldwin, M. S., \& Hayes, G. R. (2016). Would you be mine: Appropriating minecraft as an assistive technology for youth with autism. In Proceedings of the 18th International ACM SIGACCESS Conference on Computers and Accessibility (pp. 33-41). Reno, NV: ACM.

Schuller, B., Marchi, E., Baron-Cohen, S., Lassalle, A., O'reilly, H., Pigat, D., ... Golan, O., (2015). Recent developments and results of ASC-Inclusion: An integrated internet-based environment for social inclusion of children with autism spectrum conditions. In Proceedings of the of the 3rd International Workshop on Intelligent Digital Games for Empowerment and Inclusion (IDGEI 2015) as part of the 20th ACM International Conference on Intelligent User Interfaces, IUI 2015 (9-16). Atlanta, GA: ACM.

Spiel, K., Malinverni, L., Good, J., \& Frauenberger, C. (2017). Participatory Evaluation with Autistic Children. In Proceedings of the $2017 \mathrm{CHI}$ Conference on Human Factors in Computing Systems (pp. 5755-5766). Denver, CO. ACM.

Stendal, K., \& Balandin, S. (2015). Virtual worlds for people with autism spectrum disorder: a case study in second life. Disability and rehabilitation, 37(17), 1591-1598. doi:10.3109/09638288.2015.1052577

Walsh, G., Druin, A., Guha, M. L., Bonsignore, E., Foss, E., Yip, J. C., Joshi, A., (2012, June). DisCo: a co-design online tool for asynchronous distributed child and adult design partners. In Proceedings of the 11th International Conference on Interaction Design and Children (pp. 11-19). Atlanta, GA: ACM.

Walsh, G., Druin, A., Guha, M. L., Foss, E., Golub, E., Hatley, L., Franckel, S., (2010, April). Layered elaboration: a new technique for co-design with children. In Proceedings of the SIGCHI Conference on Human Factors in Computing Systems (pp. 1237-1240). Bremen, Germany. ACM.

Author biographies

Dr Tessa Roper is a Research Fellow in the Human Factors Research Group at the University of Nottingham. Her research interests are related to involving users in the design of novel technologies, and she has expertise in the development and use of immersive technologies for learning.

Dr Laura Millen Dutka completed a PhD at the University of Nottingham investigating methods for supporting participatory design with children with autism spectrum conditions. She has worked in Human-Computer Interaction in both academic and industrial settings, and currently works as an HMI specialist at Jaguar Land Rover.

Dr Sue Cobb is Associate Professor and Head of the Human Factors Research Group, University of Nottingham. She has over 20 years' experience in user-centred design 
research with specific interest in user involvement in development and application of products and novel interactive technologies for special education and rehabilitation.

Dr Harshada Patel is a Senior Research Fellow in the Human Factors Research Group at the University of Nottingham. She is a chartered research psychologist and her main research interests are in user requirements generation, the usability and evaluation of new technologies, and understanding and supporting collaborative work. 